\title{
The characteristics of euphemism in American News English
}

\author{
Zhao Hui Min ${ }^{1, \text { a }}$ \\ ${ }^{1}$ Bohai university, Jinzhou, 121013 China \\ ahmzhao2008@163.com
}

\begin{abstract}
Keywords: American English; News English; euphemism; language study; statistical research.
\end{abstract}
\begin{abstract}
In daily communication, the speaker tends to use Euphemism to express the speaker's thoughts in an indirect way, in order to reduce the disturbing and offensive to the listener. Euphemism, which comes from the worship and awe of the supernatural power, has been deeply rooted in the social life, and deeply reflects the social and cultural values of a country. To a large extent, the use of euphemism depends on context. As a mass media, news reports provide us with a lot of information, covering all parts of the world, involving various fields, and deeply affect people's lives. The language of news report has the characteristics of accuracy, simplicity, authenticity and timeliness. In addition, the news media as a communication tool, but also has the characteristics of publicity, publicity and so on. Due to the vagueness and indirect features of euphemism, euphemism plays a special and important role in the news reports. The main function of euphemism is to protect the face from the author and the reader from all kinds of offensive, and ultimately safeguard the interests of politicians and the government. Specifically, these offensive terms include taboo words or topics that are more sensitive to both parties, such as political or social issues.
\end{abstract}

\section{Introduction}

Euphemism was used a lot in journalism English in order to show the journalist intention nicely as well as to help the readers to overcome certain psychological barrier and eliminate some unhappy association. The main principals of news language are authentic, accurate and prompt; however, euphemism takes roundabout as its characteristics which show the function of beautification, smoothness and inflexion and so on. In journalism English, euphemism transfers the intention of journalists as well as its social meaning and cultural connotation. Lots of journalism English is involved in our reading materials. As an English learner, we must know the use of euphemism in journalism English, and then we can comprehend the intention of journalism to improve our ability of comprehension and the speed of reading. Since 1970s, euphemism has been a common phenomenon in journalism, which always brings special effects to journalistic language. More and more scholars have had high spirits to study euphemism in journalism English, but they seldom gave the reason why euphemism emerged in journalism English. This paper will discuss the function and classification of euphemism in journalism English [1], then set forth the social meaning and connotation, at last give some reasons of euphemism emerging in journalism English.

\section{Studies on Euphemism in Journalism English}

\section{Studies on Euphemism.}

In 1981, the British linguist Hugh Rawson published A Dictionary of Euphemism and Other Doubletalk, which sums up the dictionary of British and American linguists in the aspect of euphemism, domestic scholars give it high marks. In 1983, the American scholars, Newman and Sliver published a dictionary Kind Words - a Treasure of Euphemisms, which describes in detail the euphemism of the origin, history, development and change. In 1985, DJ Enrich published a Proceeding book Fair of Speech, the Use of Euphemism, which collected many euphemisms in papers for future research. In 1991, Allen and Burbidge published the book Euphemism and Dysphemism, from the pragmatic point of view, which research English euphemism, and it is very useful, but most euphemism researchers refer to one of the writings. 


\section{An overview of academic literature.}

Dr. Mustafa. Shazali. Mustafa published The Interpretation of Implicative: a Comparative: Study between Implicative in Linguistics and Journalism in the Journal of Language Teaching and Research. (Vol.1, pp.35-43), he introduced the origin, definition and function of the journalism English. Bill Brohaugh issued his article Cantankerous Commentary on What We Speak and Why We Speak It (at 12:12am 01.16.09), he introduces the social function and connotation of euphemism. In the Euphemism in the Journalism English, Tan Menglin expounded the definition and classification of euphemism. Guo Liang and Gong Yi set forth the pragmatic functions of euphemism in their paper On Pragmatic of Euphemism in Journalistic English.

\section{Origin of Euphemism.}

Euphemism is a linguistic phenomenon, from the taboo. In many societies, because of cultural, religious, political, customs and other reasons, people should avoid many things and can not engage in many behaviors, which formed social taboo. It is usually said by people. In the course of people's daily interactions, because their name could not be mentioned, it gradually developed into a language of taboo. However, for various reasons, people also can not completely avoid them. At this time, people had to express in other languages instead of them indirectly. This alternative language means euphemism. In the ancient Greek, Prefix "eu” means good, well or sounding well; root "premise" views speech, the literal meaning of "words of good men" or "good speech". Therefore, the Oxford High Class dictionary is to explain the euphemism for "in a pleasant, sounds pleasing to the ear [2], instead of unpleasant words which sounds harsh. As a linguistic phenomenon, Euphemism is from the social taboo."

\section{Definition of Euphemism}

\section{Overview of relevant definitions.}

The word "euphemism" comes from the Greek, eu--means "good", and -pheme-, "speech" or "saying", and together it means literally "to speak with good words or in a pleasant manner". Euphemism, as a cultural phenomenon as well as a linguistic concept, has attracted people's attention for a long time. It has long been a topic of much interest. Generally speaking, people would use more euphemisms in communicating with the opposite sex; women would use more than men would; older people would use more than younger generations. People would more use euphemisms in "power" relations than in close relations. People with higher education would use more euphemisms. The above factors: age, sex, social status, education, etc. do not work separately. In communicating, they are interlaced with each other and guide our choice of euphemisms. Whether to use euphemisms or taboo words also depends, to a large extent, on the attitudes of participants and the purpose of conversations. Newspaper euphemism used in English can be divided into two categories: Used in the news related with the life of the traditional euphemism, euphemism called Language (traditional euphemisms). Traditional euphemism often used to avoid old age, sickness, death, sex, nude, drawing, Caesar and other taboo things, such as (Death) mean pass away, "euphemism” comes from the Greek and is being gradually accepted by the people all over the world.

\section{Function of Euphemism in English.}

Euphemism is common phenomenon in the process of using human language; people are talking about unpleasant or embarrassing things and they use polite phrase. Euphemism should not be used to express a person or thing in direct communication. In the process of language communication, it is sometimes necessary to taboo what people say (or write) some words, which are taboo words. However, in some cases, in speech delivery, some taboo words have to be said; can not be avoided, so rather indirect way of expression, euphemism came into being. In the information age, Reading English newspapers is one of the main channel to access information. Therefore, to acquire new characteristics of English news language, reading newspapers acquires more and more American attention. There involves very extensive use of euphemism in English news, but they all reflect 
various degrees of speech and behavior guidelines, and most people's patterns and values, and morality, which have been recognized in today's American society .Next English Euphemism functions in the news will be talked about[3].

\section{Function of Politeness.}

Euphemism is a frequent use of language strategy in the process of disseminating information. In the news report, there often exist "threat face behavior", so in order to take into account the reported person's face; euphemism language has become a strategy which is often used, such as: Nixon's proposals have been hailed as sound if not original. But this appraisal of his own stewardship sometimes seems more generous than candid. In addition, the euphemism in news Language is also reflected in a large number of professional reputations. Any kinds of work, which are reported in the media, become a profession. There are many professional English euphemisms. The main purpose of using professional euphemism is to be in the traditional sense of the "low" level industry "decent of." There is variety of euphemisms' professional manner, one of which is artificially pushed in higher occupational status. For example: the waiter or waitress in the restaurants is called "dining-room attendants ", the waiter was promoted to administrator status.

\section{Function of Concealment.}

There is another reason for people using euphemism in communication is that euphemism is fuzzy, the use of euphemism often has a deceptive purpose, and it is like a beautiful and attractive coat which makes people suddenly see things in the inner essence. The ugly hidden in the beautiful and cover up truth, The usual approach is to use the fuzzy concept in the media of reporting war, which let people play down fear and loathing of the war , to cover the purpose of the war and not to arouse the public's antiwar sentiments. On the other hand, politicians use the euphemism to cover up the truth and not to disclose their ugly society Evil, or not to sue others. These euphemisms are: (1) is used to cover up the poverty, crime and other serious social problems such euphemism language. Such as: News in English commonly used "industrial action" to represent "strikes"; with "substandard housing" instead of "slum" to protect the occupants and the government's self-esteem. Standard of living is lower than people below the poverty line, known as "the underprivileged" or "the disadvantaged" or "the have notes" or "the lower income group"; poverty, debt-ridden people called "negative saver"; factory clearly is fired the workers, he was known as the "lay off", "give the walking ticket"; "economic crisis" is known as recession or depression . (2) Is used to cover up the real aggression of war. In 2003, Americans In the war against Iraq, in order to cover up its atrocities, So military exercises bombs, artillery shells, guided bombs caused civilian casualties is the collateral damage ,the U.S. military mistakenly hit British, is the friendly fire; clearly a use of force against Iraq, but shy away from these words, such as at war attack the words and so on, but with disarm Iraq, taken against Iraq aspire-emptive action; As British forces defeat on the battlefield in Iraq, it must be an adjustment of the front (3) Is used to cover up the scandal of political . Such as: the so-called "Watergate" refers to the English euphemism used to replace scandal of the word suffix:-gate. After the Watergate in 1972, the term of Watergate was used to refer to any similar or larger political events, but not as the straight use the affair or scandal. Such as debate gate (debate on the scandal: 1980 Presidents Reagan and Carter were the last TV debate before the election, Reagan has a debate text on the Carter and Reagan to the text, Reagan thus significant in this debate between the upper hand), Korea gate (South Korea scandal: that a South Korean businessman to buy U.S. lawmakers shocked by the U.S. Congress Events), and Monica gate (Monica scandal: Monica Lewinsky and the President of the United States Clinton's peach events), etc[4].

\section{Use of Euphemism in Journalism English}

\section{Function of Taboo.}

There is a linguistic taboo in any culture, any society, Anglo-American society is no exception. Over the years, an Anglo-American people always think that it is a symbol of social civilization of avoiding 
it. Most part of taboo is about sex, excretion of human physiological functions, some parts of the body and is not profane words of some god ghost. These are also in news body. Euphemism originates from verbal taboo, and verbal taboo originates from religious superstition, which reflects the importance of social psychology in the origin of euphemism. Taboo and euphemism are two closely related cultural and linguistic phenomena of human society. We can't talk about one without referring to the other. Almost any of the cultures in the world has its own taboo. The word "taboo" is from Polynesian, meaning "sacred" or "accused". And there are two aspects of verbal taboo: one is word-fetishism; the other is the forbidden use of language. In uncivilized and crude society, the primitives were often confronted with puzzling and threatening situations and phenomena, such as death and diseases. As they couldn't understand and explain the extraordinary events and performance, success and failure, they worshiped, and even dreaded the supernatural. Such psychology leads to superstition, and then developed into Fetishism. The specific language was also defied, that is, Word Fetishism. Out of the worship of gods and ghosts, their names must be avoided. So their names became the earliest taboo words, and other words used to replace them became the earliest euphemisms. When a taboo word is abandoned, people have to find another word to fill up the vacancy. That's the way of euphemism being created. In both the English and the Chinese language speech community, the most obvious taboos have to do with bodily functions, body parts, death etc... Taboo changes over time. New taboos are racism, ageism, and taboos concern other social and commercial life. Modern taboos are motivated more by notion of decency, politeness, decorum and communicative appropriateness than by pure fear or sense of danger in earlier taboo practice. They reflect sensitivity and respect for others' feelings. Meanwhile, euphemism develops with taboo, so euphemistic words and expressions not only allow us to talk about unpleasant things and disguise or neutralize the unpleasantness, e.g., the subjects of sickness, death and dying, unemployment, and criminality, but also allow us to give labels to unpleasant tasks and jobs in an attempt to make them sound almost attractive.

Euphemism is a linguistic phenomenon, which is used as an important means of regulating interpersonal relations. With the harmonious development of society, speaking skills and good interpersonal skills increasingly have profound impact on people's lives. People try to avoid Straightforwardness and prefer to use euphemisms to express a good impression for the listeners.

\section{Classification of Euphemism in Journalism English.}

Euphemism is a frequent use of language strategy by people in the process of disseminating information. As a social phenomenon, euphemism has aroused great interest in academic of language (1979 to 2005 China Journal Network can be found in academic research related to Euphemism 731), but whether is journalism, or social linguistics, pragmatics (the two major branches of linguistics), Euphemisms in English on the news have very few studies. In fact, the English in news euphemism is used everywhere. According to the user's purposes, we can divide the euphemism in journalism English into: altruism, Fan Li, self-interest categories.

\section{Encompassing Euphemism.}

Encompassing euphemism: It can make the listener feel pleasant; the speaker appears to be elegant. Compared with pure altruistic euphemism for people who have been involved in face and the dignity, it is also affected by the "Elegant principle" domination. Any culture has its own taboo subject or word, as the public communication tools, in media reports, the reporters often concern their own position and concern identity, to make use of gentle, vague words. Self-serving euphemism: speakers do not mean what they think just for the interest of their group in news reports, such as the euphemism of "war" and "Watergate" and other euphemisms. Media reports of war, the usual approach is to use a particular fuzzy concept, which can help people play down the fear and loathing of war, the purpose of covering the war in order to free public from arousing sentiment against the war. So military exercises bombs, artillery shells, guided bombs caused civilian casualties is the collateral damage ,the U.S. military mistakenly hit British, is the friendly fire; clearly a use of force against Iraq, but shy away from these words, such as at war attack the words and so on, but with disarm Iraq, taken against Iraq[5]. As British forces defeat on the battlefield in Iraq, it must be an adjustment of the front the 
so-called "Watergate" refers to the English euphemism used to replace scandal of the word suffix:-gate. After the Watergate in 1972, the term of Watergate was used to refer to any similar or larger political events, but not as the straight use the affair or scandal. Such as debate gate (debate on the scandal: 1980 Presidents Reagan and Carter were the last TV debate before the election, Reagan has a debate text on the Carter and Reagan to the text, Reagan thus significant in this debate between the upper hand), Korea gate (South Korea scandal: that a South Korean businessman to buy U.S. lawmakers shocked by the U.S. Congress Events), and Monica gate (Monica scandal: Monica Lewinsky and the President of the United States Clinton’s peach events), etc.

\section{Summary}

In summary, the euphemism is on the performance of language from which people seek in the social communication. It is created for ideal communication effect. It is used for replacing the taboo language, the discussion sensitive topic generally. The using of euphemism may avoid stimulating and comfort for the human. When replacing the taboo language, it can eliminate vague, and give people elegant impression; simultaneously the euphemism sometimes may be showy, and sometimes also have the sense of humor. Being good at euphemizing is a manifestation of high accomplishment. Using excessively, it would give people affected feeling. Therefore, we must pay attention to the usage of euphemism in the process of communication. In brief, understanding and having a good command of the euphemism can be understood more effectively. At the same time, it also has the inspiration and guiding function of the sense of Trans-culture.

\section{Acknowledgements}

This work is supported by Social Science Foundation of Liaoning Province (No. L15DWW005) and Bohai University Teaching Reform Project (No.BDJG15QNB002).

\section{References}

[1] Zhang Qu. Chinese Journal of Chengdu University (SOCIAL SCIENCE EDITION) from the perspective of euphemism and taboo [J]. Journal of (SOCIAL SCIENCE EDITION). 2007 (04).

[2] Zhao Qi, President of the American political speech in literature. The euphemism [J]. Journal of Changchun Normal University 2005 (01).

[3] Yao Jianpeng. Euphemism culture of [J]. Shandong: Foreign Language Teaching (04) 2003.

[4] Shao Junhang, fan Weiwei. Euphemism classification [J]. Journal of Xinyang Normal University (PHILOSOPHY AND SOCIAL SCIENCES EDITION) 2002 (01).

[5] Li Guonan. Euphemism and religion [J]. Fujian foreign language. 2000 (03). 